\title{
PARTS AND PORTIONS OF BUILDINGS
}

\author{
D. Kolston*
}

\section{INTRODUCTION}

In comparison with Chapter 8 , the section dealing with "Parts and Portions of Buildings" has been significantly extended.

The extension is in line with the multi-term-evaluation approach which is used in the code to establish the seismic force on the building.

The ad hoc Committee of SEAOC in its report of October 1971 on the direction in which the basic seismic design criteria should be going, indicated (amongst other things) that lateral force requirements and "codes resulting there from" must be simplified to the fullest extent possible.

It further indicates that .......... "such maximum simplicity should be consistent with the complexity of the problem. Our limited knowledge of the level of forces or performances of the materials used is not consistent with a degree of un-warranted complexity. Time and money should not be spent on unnecessary precision but on better design, detailing and inspection."

Although the committee was well aware of these considerations, it was considered appropriate to try and provide a method of design for this section of the code which would make designers aware of the reasons for the choice of the various coefficients, the relationship with the supporting structure, their use and the nature of the part itself.

The previous code $\mathrm{K}$ value was simple to use but inadequate in other respects. Over the years, the Standards Institute and committee members have been requested to explain to many designers why certain $\mathrm{K}$ values had been chosen or, alternatively, why no account was taken of apparent logical differences which should be applied to various members because of location in the building, superior material quality (masonry parapets versus precast concrete elements for instance), type of building (stiff versus flexible) etc.

Other Codes generally do not provide such detailed requirements to the design of parts of buildings. The extent of damage to non-structural elements and contents of buildings experienced during earthquakes is an indication that more careful consideration is warranted.

The Code approach will make it possible to readily amend the present coefficients in a logical manner in the light of further experience.

\footnotetext{
* Consulting Engineer, Structon Group,
} Wellington.
In cases where the designer considers that a detailed examination of the seismic force on the part is not warranted, the Code provides maximum values for $C_{p}$ with the formula $\mathrm{F}_{\mathrm{s}}=\mathrm{C}_{\mathrm{p}} \mathrm{W}_{\mathrm{s}}$.

\section{DESCRIPTION AND DISCUSSION OF CODE REQUIREMENTS}

The basic philosophy behind this part of the code is that parts of buildings are structural elements of which the behaviour during an earthquake is affected by the nature and the response of the building to which the part is connected and by the nature etc. of the part itself.

The difference with Chapter 8 is that the new Code provides coefficients for the various factors related to parts of buildings in the same manner as the seismic design coefficient $C_{d}$ factors are given for the design of the building structure.

The part factors are concerned with aspects such as risk, material, type and position of the part under consideration.

The code determines the seismic force $F_{S}$ on a part of a building with the formula $F_{s}=C_{p} \cdot W_{p}$ of which the factor $C_{p}$ can either

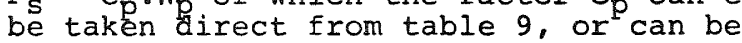
calculated from $c_{p}=c_{p 1} \cdot c_{p 2}$

where

$\mathrm{C}_{\mathrm{pl}}=\mathrm{K}_{\mathrm{p}} \cdot \mathrm{R}_{\mathrm{p}} \cdot \mathrm{C}_{\mathrm{d}}$

and

$\mathrm{C}_{\mathrm{p} 2}=\mathrm{s}_{\mathrm{p}} \cdot{ }^{\mathrm{M}} \mathrm{p}$.

The factor $\mathrm{Cp} 2$ is purely related to the part itself and is the product of the structural type factor $S_{p}$ and the material factor $M_{p}$ of the part.

The factor $C_{p l}$ is a hybrid as it incorporates the flactor $c_{d}$, which links the part of the building to the behaviour of the building as a whole.

The factor $C_{d}$ is the horizontal seismic design coefficient of the building and will have been determined by the designer by the time that the design of the parts of the building is being carried out.

The factors $K_{p}$ and $R_{p}$ are "position" coefficients of the part and part-riskfactors respectively.

The structural type factor $S_{p}$ of the part is related to the "ductility" of the part. An examination of table 8 in the code makes it clear that the ductility rating of parts has been chosen without the stringent detailing requirements related to 
primary members, which are the principal energy dissipating elements.

The rating is more related to assumed or known behaviour of various types of parts during earthquakes.

It should be realised that the assumptions made for the parts of buildings are more arbitrary than for the building structure itself. For instance, the inclusion of the $c_{d}$ coefficient in $C_{p l}$ accepts the assumption that the force on the part is determined by the acceleration response of the building during the earthquake.

Although this assumption is probably the most logical for fixed items, it is clear that velocity and displacement relationships to acceleration (as expressed in a tri-partite representation of response spectra) are only approximate for nonharmonic motions.

Material factors $M_{\text {p }}$ are the same as the material factors $M$ for the building.

Maximum accelerations for a building are determined by its yield capacity for yielding structures or by the elastic damped response for non-yielding structures.

Theoretically, therefore, the $c_{d}$ value should provide the "fuse" which determines the maximum loading on the part.

Due to the standards of design, undercapacity factors and general uncertainties, it is necessary to assume a building overcapacity.

The over-capacity has been taken as $50 \%$ and the value for $\mathrm{K}_{\mathrm{p}}$ taken as $1.5 \mathrm{~K}_{\mathrm{X}}$. in which $K_{x}$ is the local seismic force distribution factor. The minimum value of $\mathrm{K}_{\mathrm{p}}$ is 1.5 .

The risk factor $R_{p}$ for parts is partly determined by the consideration of redundancy (as for cantilever versus non-cantilever structures) and partly by the possible results of danger at failure.

A failure of a partition near a means of egress would generally be more serious than a failure of any other partition on a floor.

The risk factor acts as a safety factor against overloads. This is necessary if it is realised that our El Centro-type design earthquake is certainly not the maximum. earthquake to be expected in zone $A$.

The chosen $R_{p}$ values form part of the factors indicated in table 9 .

They have been derived from the following rough considerations :-

Class of Risk

1. "Normal" risk (partitions etc.)

2. Greater than "normal" risk (associated with adjoining 1.33 public places, means of egress etc.)

3. High risk (sprinkler systems etc)
4. Extreme risk (toxic liquids, parapets etc.)

Table 9 provides the $C_{p}$ factor which designers can use direct (and which should be regarded as a maximum value) and also the minimum value for $C_{p}$.

Both these limits are required because the combination of the lowest factors which constitute the $C_{d}$ value (say 0.8 for $s$ and $M$ combined with $I$ for $S_{p}$ and 0.8 for $M$ ) or of the highest factors for all coefficients could obviously result in "K values" which are either too low or too high.

Extreme values have been calculated from the maximum forces which parts are likely to have to resist from the amplified design earthquake adjusted for the relative ductility of the part.

These adjustments for relative ductility have been established in the same manner as considerations which apply to the ductile behaviour of the building as a whole.

Assume a Zone $A$, class III, reinforced concrete, ductile framed building, with a period lower than 0.45 seconds, 2\% damping and an amplification factor of 3.2 .

$C_{d}=$ C.I.S.M.R. $=0.15 \times 1.0 \times 0.8 \times 1$

$$
\mathrm{x} 1=0.12
$$

If we assume an overstrength of 1.5 for the building, the "fuse" is equivalent to $c_{\mathrm{d}}=1.5 \times 0.12=0.18$.

The Chapter 8, K, El Centro "scale" factor can then be established.

$\mathrm{K} \times 0.33 \times 3.2=0.18$

$$
\mathrm{K}=\frac{0.18}{0.33 \times 3.2}=0.17 \text {, say } \mathrm{K}=0.2
$$

If we consider a less ductile building for which $S=1.6, K=2 \times 0.17=0.34$, say $\mathrm{K}=0.3$.

For brittle structures or for structures where no ductility demand can be tolerated, $c_{\mathrm{d}}=0.33 \times 3.2=1.06 \mathrm{~g}$ and $\mathrm{K}=1.0$.

The range of " $\mathrm{K}$ values" varies from 1.0 for brittle structures to 0.2 for ductile elements.

This scaling factor of 5 is used in table 9 (and added safety is provided by the $\mathrm{R}_{\mathrm{p}}$ factor).

For single storey buildings, the peak response to $\mathrm{El}$ Centro has been taken as 1.8 and for the top of multi-storey buildings as $2.33 \times 1.7$.

E1 Centro

N.S.

Single Storey (S.S.) $1.8 \mathrm{x}$

$0.33=0.60 \mathrm{~g}$

Multi Storey (M.S.) $2.33 \times 1.7 \times 0.33=1.33 \mathrm{~g}$ 


\begin{tabular}{|c|c|c|c|}
\hline Group & $\begin{array}{l}\text { Scale } \\
\text { Factor }\end{array}$ & S.S. & M.S. \\
\hline $\begin{array}{l}\text { 1. Fully Ductile } \\
\text { Members } \\
\text { Columns, double } \\
\text { reinforced walls, } \\
\text { suitably reinforced } \\
\text { walls bands R.C. } \\
\text { diaphragms (high } \\
\text { damping) }\end{array}$ & 0.2 & 0.12 & 0.27 \\
\hline $\begin{array}{l}\text { 2. Partially Ductile } \\
\text { Braced diaphragms, } \\
\text { centrally rein- } \\
\text { forced walls, wall } \\
\text { bands not rein- } \\
\text { forced for ductility } \\
\text { Column cantilevers, } \\
\text { pipe lines. }\end{array}$ & 0.3 & 0.18 & 0.40 \\
\hline $\begin{array}{l}\text { 3. Low Ductile or where } \\
\frac{\text { little ductility is }}{\text { tolerable }} \\
\text { Sprinklers, wall } \\
\text { cantilevers }\end{array}$ & 0.5 & 0.30 & 0.67 \\
\hline $\begin{array}{l}\text { 4. Brittle } \\
\text { Unreinforced masonry } \\
\text { veneers }\end{array}$ & 1.0 & 0.60 & 1.33 \\
\hline
\end{tabular}

The tabulated limits apply to zone A, class III buildings and are to be adjusted for the Importance factor I for seismic zones $B$ and $C$ as indicated in clause 3.4 .9 .2 .

Examples of the application of clause 3.4.9 and table 9 have been given in Appendix A.

Clause 3.7 on "Interconnection and horizontal support" includes general statements on these requirements which are generally similar to the Chapter 8 provisions.

The code includes a special clause for the design of suspended ceilings.

This was considered necessary by the committee because previously existing suspended ceiling systems tended to disregard all considerations for aseismic behaviour.

The obvious hazard which unsatisfactory ceiling systems can cause has been experienced in many earthquakes both in New Zealand and overseas. And the functions of important buildings in class I and II have been disrupted by these elements including lighting fixtures which form part of the system.

The requirements are already incorporated by suppliers who are aware of these provisions and it appears that there are no real problems or significant costs involved to comply with the requirements.

Special mention is made of the need to design lift machinery, guides and stand-by electrical equipment for a loading of $\mathrm{lg}$ in any direction. These requirements are started to be recognised by the industry involved, especially after the
San Fernando earthquake.

It is now realised that high rise buildings can be completely non-operational if lifts and items like air-conditioning are not functioning after an earthquake even when the structure has survived the disturbance without serious damage to other parts. This consideration might be one of the many reasons why the need for high-rise buildings should be critically examined.

\section{CONCLUSION}

Although the "Parts and Portions" section of the Code appears to be complicated, the complication is not really very serious for the designer of a particular building.

Similar to the Static Force Analysis of the building itself, the multi-term evaluation will create an awareness of relative merit of performance for various forms of structure, ductility, type of material etc.

Maximum values listed are available for designers who do not consider the more detailed analysis to be appropriate.

\section{APPENDIX :}

Examples of the calculation of the seismic force $F_{S}$ on "Parts and Portions of Buildings" in accordance with clause 3.4 .9 .

\section{Example 1}

A reinforced concrete boundary wall on the roof of a ductile frame, reinforced. concrete, class III, low risk, 8 storey high building in zone $B$ on a flexible subsoil.

A. In accordance with the maximum value as given in Table 9 .

$$
F_{s}=C_{p} \cdot W_{p}
$$

from Table 9, item 1 (a) (ii), for zone A, class III.

$$
c_{p}=0.5
$$

From clause 3.4.9.2, for zone B, class III

$$
\begin{aligned}
& C_{p}=0.83 \times 0.5=0.42 \\
& F_{s}=0.42 \mathrm{~W}_{p} .
\end{aligned}
$$

B. As calculated from the formula

$F_{s}=C_{p 1} \cdot C_{p 2} \cdot W_{p}$

in which $c_{p l}=k_{p} \cdot R_{p} \cdot c_{d}$

and

$$
c_{\mathrm{p} 2}=\mathrm{s}_{\mathrm{p}} \cdot \mathrm{M}_{\mathrm{p}}
$$

for the 8 storey building, take $k_{x}=1.8$ from clause $3.4 \cdot 9.4$

$$
\mathrm{K}_{\mathrm{p}}=1.5 \times 1.8=2.7
$$

from Table 9, item l(a) (ii),

$$
R_{p}=1.33
$$

$K_{p} \cdot R_{p}=2.7 \times 1.33=3.6$ 
For building (clause 3.4.2)

$$
C_{d}=C \cdot I \cdot S \cdot M \cdot R \text {. }
$$

$\begin{array}{lll}C=0.115 & \text { from Figure } 3 & \text { (with } T=0.8 \text { ) } \\ I=1.0 & \text { from Table } 4 & \\ S=0.8 & \text { from Table } 5 & \\ M=1.0 & \text { from Table } 6 & \\ R=1.0 & \text { from Table } 7 & \end{array}$

so that $c_{d}=0.115 \times 1.0 \times 0.8 \times 1.0 \times 1.0$

and $C_{p I}=3.6 \times 0.09=3.2$

$c_{p 2}=s_{p} \cdot{ }^{M}$.

$s_{p}=1.0$ from Table 8

$M_{p}=1.0$ from Table 6

$c_{p 2}=1.0 \times 1.0=1.0$

$\mathbf{F}_{\mathbf{s}}=0.32 \mathrm{Wp}$.

C. Check minimum value from Table 9 .

$C_{p \min }=0.3$ from Table 9 for zone $A$, class III.

From clause 3.4.9.3, for zone $B$ :

$c_{p \min }=0.83 \times 0.3=0.25$

For design use $F=0.32 \mathrm{w}_{\mathrm{p}}$

(For comparison:

Chapter 8: $\Vdash=4.0$

$F_{S}=4 \times 1.25 \times 0.09=0.45 \mathrm{~W}_{\mathrm{p}}$

Seaoc 1974

$\left.\mathrm{F}_{\mathrm{s}}=1.4 \times 0.2 \mathrm{~W}_{\mathrm{p}}=0.28 \mathrm{~W}_{\mathrm{p}}\right)$

Example 2

A cantilevered storey, consisting of free-standing, cantilevered, ductile, reinforced concrete columns, on top of a one storey, class II, low risk, category 6 shear wall building in zone $A$.

A. In accordance with the maximum value as given in Table 9

$$
\mathrm{F}_{\mathbf{s}}=\mathrm{C}_{\mathrm{p}} \cdot \mathrm{w}_{\mathrm{p}} \cdot
$$

from Table 9 , item $2(a)$ (i): $C_{p}=0.3$ for

from clause 3.4 .9 .2 , for a class II building in Zone A, (refer Table 4).

$$
\mathrm{F}_{\mathrm{s}}=1.3 \times 0.3 \mathrm{~W}_{\mathrm{p}}=0.39 \mathrm{w}_{\mathrm{p}} \text {. }
$$

B. As calculated from the formula

$F_{s}=C_{p l} \cdot C_{p 2} \cdot W_{p}$.

from clause 3.4.9.4, for a single storey building, $k_{p} \operatorname{min.}=1.5$

from Table 9, item 2 (a) (i)

$$
R_{p}=1.5
$$

$K_{p} \cdot R_{p}=1.5 \times 1.5=2.25$
For building (clause 3.4.2) $\mathrm{C}_{\mathrm{d}}=$ C.I.S.M.R.

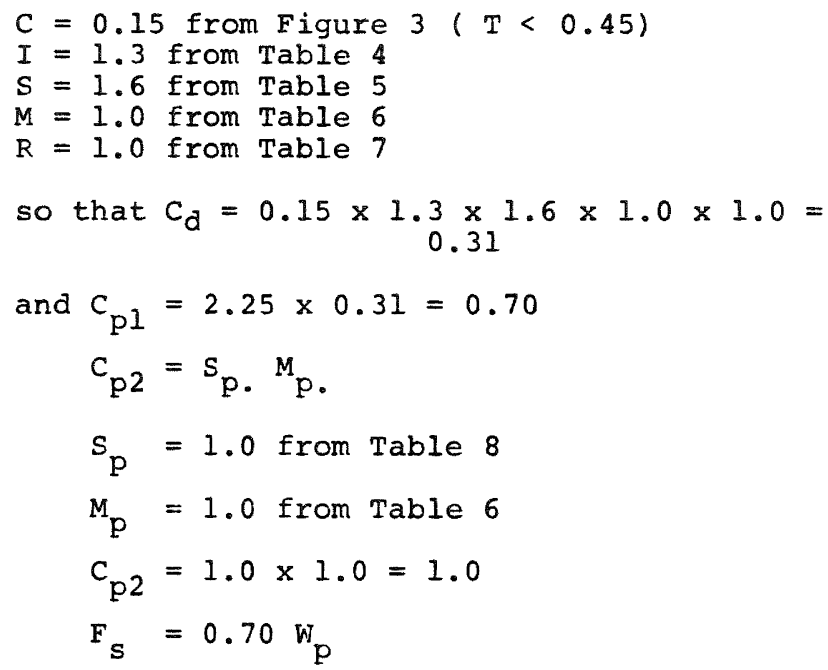

C. Check minimum value from Table 9.

$C_{p \text { min }}=0.3$ from Table 9 item 2 (a) (i) for Zone A, Class III

from clause 3.4 .9 .3 , for class II

$c_{\mathrm{p} \min }=1.3 \times 0.3=0.39$

For desigr use $\mathrm{F}_{\mathrm{S}}=0.39 \mathrm{~W}_{\mathrm{p}}$.

(for comparison:

Chapter 8: $\mathrm{K}=3.0$

$F_{S}=3 \times 1.25 \times 0.16=.60 \mathrm{w}_{\mathrm{p}}$.

Seaoc 1974:

not covered).

\section{Example 3}

A boiler, in a boiler room, located at the top of a 12 storey, ductile steel framed, Class I, low risk, building in zone $C$ on a rigid subscil.

A. In accordance with the maximum value as given in Table 9 .

$$
\mathrm{F}_{\mathrm{s}}=\mathrm{C}_{\mathrm{p}} \cdot \mathrm{w}_{\mathrm{p}} \cdot
$$

from table 9, item 9(ii), for zone A, Class III

$$
c_{p}=1.3
$$

from clause 3.4.9.2., for zone C, class $I$.

$$
c_{p}=1.3 \times 2 / 3 \mathrm{I} \text {. }
$$

$I=1.6$ from Table 4

$$
\begin{aligned}
& c_{p}=1.3 \times 2 / 3 \times 1.6=1.39 \\
& F_{s}=1.39 \mathrm{~W}_{p} .
\end{aligned}
$$

B. As calculated from the formula $\mathrm{F}_{\mathrm{s}}=\mathrm{C}_{\mathrm{pl}} \cdot \mathrm{C}_{\mathrm{p} 2} \cdot \mathrm{W}_{\mathrm{p}}$

for the 12 storey building, take $\mathrm{K}_{\mathrm{x}}=1.85$

from clause 3.4 .9 .4

$$
K_{p}=1.5 \times 1.85=2.77
$$


from table 9, item 9 (ii)

$$
R_{p}=2.0
$$

$K_{p} \cdot R_{p}=2.77 \times 2.0=5.54$

For building (clause 3.4.2)

$$
\mathrm{C}_{\mathrm{d}}=\text { C.I.S.M.R. }
$$

$C=0.05$ from Figure $3(T=1.2)$

$I=1.6$ from Table 4

$S=0.8$ from Table 5

$M=0.8$ from Table 6

$R=1.0$ from Table 7

so that $c_{d}=0.05 \times \frac{1.6 \times 0.8 \times 0.8 \times 1.0=}{0.05}=$ and $\mathrm{C}_{\mathrm{pl}}=5.54 \times 0.05=0.28$

$$
c_{p 2}=s_{p} \cdot M_{p}
$$

$S_{p}=1.0$ from Table 8

$\mathrm{M}_{\mathrm{p}}=0.8$ from Table 6

$C_{\mathrm{p} 2}=1.0 \times 0.8=0.8$

$F_{S}=0.28 \times 0.8=0.22 W_{p}$.

C. Check minimum value from Table 9

$C_{p \min }=0.9$ for zone $A$, class III

from clause 3.4 .9 .3 ., for zone $C$, class $I$.

$c_{p \min }=0.9 \times 0.67 \times 1.6=0.96 \mathrm{w}_{\mathrm{F}}$.

For design use $F_{s}=0.96 \mathrm{~W}_{\mathrm{p}}$

(for comparison:

Chapter $8 \quad K=2$

$F_{s}=2 \times 1.25 \times 0.08=0.20 \mathrm{~W}_{\mathrm{p}}$.

Seaoc 1974

$\left.\mathrm{F}_{\mathrm{S}}=1.4 \times 0.5 \mathrm{~W}_{\mathrm{p}}=0.70 \mathrm{~W}_{\mathrm{p}}\right)$ 